\title{
Identification and characterization of a novel gene differentially expressed in zebrafish cross-subfamily cloned embryos De-Sheng Pei ${ }^{1,2}$, Yong-Hua Sun*1, Chun-Hong Chen ${ }^{1,3}$, Shang-Ping Chen ${ }^{1}$, Ya-Ping Wang1, Wei Hu${ }^{1}$ and Zuo-Yan Zhu*1
}

\author{
Address: ${ }^{1}$ State Key Laboratory of Freshwater Ecology and Biotechnology, Institute of Hydrobiology, Chinese Academy of Sciences, Wuhan \\ 430072, China, ${ }^{2}$ Group of Environmental Genomics, Institute of Hydrobiology, Chinese Academy of Sciences, Wuhan 430072, China and \\ ${ }^{3}$ College of Life Science, Wuhan University, Wuhan 430072, China \\ Email: De-Sheng Pei - peidesheng@yahoo.com.cn; Yong-Hua Sun* - sunyonghua@gmail.com; Chun- \\ Hong Chen - happysailing6539@gmail.com; Shang-Ping Chen - shpchen@ihb.ac.cn; Ya-Ping Wang - wangyp@ihb.ac.cn; \\ Wei Hu - huwei@ihb.ac.cn; Zuo-Yan Zhu* - zyzhu@ihb.ac.cn \\ * Corresponding authors
}

Published: 18 March 2008

BMC Developmental Biology 2008, 8:29 doi:10.1186/147/-2/3X-8-29

This article is available from: http://www.biomedcentral.com/I47I-2/3X/8/29

(C) 2008 Pei et al; licensee BioMed Central Ltd.

This is an Open Access article distributed under the terms of the Creative Commons Attribution License (http://creativecommons.org/licenses/by/2.0), which permits unrestricted use, distribution, and reproduction in any medium, provided the original work is properly cited.
Received: 29 June 2007

Accepted: 18 March 2008

\begin{abstract}
Background: Cross-species nuclear transfer has been shown to be a potent approach to retain the genetic viability of a certain species near extinction. However, most embryos produced by cross-species nuclear transfer were compromised because that they were unable to develop to later stages. Gene expression analysis of cross-species cloned embryos will yield new insights into the regulatory mechanisms involved in cross-species nuclear transfer and embryonic development.

Results: A novel gene, K3I, was identified as an up-regulated gene in fish cross-subfamily cloned embryos using SSH approach and RACE method. K3 I complete cDNA sequence is II 06 base pairs (bp) in length, with a 342 bp open reading frame (ORF) encoding a putative protein of I I 3 amino acids (aa). Comparative analysis revealed no homologous known gene in zebrafish and other species database. K3I protein contains a putative transmembrane helix and five putative phosphorylation sites but without a signal peptide. Expression pattern analysis by real time RT-PCR and whole-mount in situ hybridization (WISH) shows that it has the characteristics of constitutively expressed gene. Sub-cellular localization assay shows that $\mathrm{K} 3 \mathrm{I}$ protein can not penetrate the nuclei. Interestingly, over-expression of $\mathrm{K} 3 \mathrm{I}$ gene can cause lethality in the epithelioma papulosum cyprinid (EPC) cells in cell culture, which gave hint to the inefficient reprogramming events occurred in cloned embryos.
\end{abstract}

Conclusion: Taken together, our findings indicated that $\mathrm{K} 3 \mathrm{I}$ gene is a novel gene differentially expressed in fish cross-subfamily cloned embryos and over-expression of $\mathrm{K} 3 \mathrm{I}$ gene can cause lethality of cultured fish cells. To our knowledge, this is the first report on the determination of novel genes involved in nucleo-cytoplasmic interaction of fish cross-subfamily cloned embryos.

\section{Background}

Nuclear reprogramming is used to describe that the transferred nucleus from partially or fully differentiated cell has the potential to direct the reconstructed embryo to develop like a normal embryo[1]. Although successful production of animal clones from somatic cells has been 
achieved in various species, many problems in offspring could not be hurdled due to incomplete nuclear reprogramming [2]. Cross-species nuclear transfer involves transferring cell nuclei of one species into enucleated oocytes of another species, which has been shown to be a potent approach to retain the genetic viability of a certain species near extinction [3]. However, most embryos produced by cross-species nuclear transfer were compromised because they were unable to develop to later developmental stages. To study inefficient reprogramming of the donor nuclei in the recipient cytoplasm from another species, nuclear transfer (NT) between two fish species was used as a model in the present study. A pioneering study on fish NT was carried out by Tung et al [4] and extensive studies on fish cross-species NT were mainly conducted in Cyprinid [5]. Recently, cross-genus cloned fish derived from transgenic common carp nuclei and goldfish enucleated eggs were generated and the somitogenesis and vertebral number of the cloned fish were consistent to the eggproviding species, goldfish (Carassius auratus), instead of the donor cell species, common carp (Cyprinus carpio) [6]. Gene expression analysis of cross-species cloned embryos will shed light on the regulatory mechanisms involved in cross-species nuclear transfer and embryonic development.

Nuclear transfer between two laboratory fish species, rare minnow (Gobiocypris rarus) and zebrafish (Danio rerio), provides an ideal model for the study of cross-species nuclear transfer. Rare minnow and zebrafish belong to different subfamily - the Gobioninae and the Danioninae $[7,8]$. Zebrafish is a notable model for developmental and genetic studies for its short sex-maturity cycle, high reproductive capacity, and transparent eggs, etc $[9,10]$. Rare minnow, a special local species in China, not only shares aforementioned advantages with zebrafish, but also has many unique traits for laboratory study such as typical eurytherm and high adaptation [11], and sensitivity to toxicity and virus $[12,13]$. Such advantages enable rare minnow to be an excellent type of experimental fish [14].

In the present study, we performed cross-subfamily nuclear transfer between zebrafish and rare minnow and obtained nuclear transfer embryos derived from zebrafish nuclei and rare minnow enucleated eggs. Using a suppression subtractive hybridization (SSH) approach, we found a novel gene - K31 over-expressed in cloned embryos, potentially participating in the improper reprogramming of transferred nuclei.

\section{Results}

Identification of $\mathrm{K} 3 \mathrm{I}$ as an up-regulated gene

To better understand the molecular events in cloned embryos, we performed nuclear transfer between two laboratory fish, zebrafish and rare minnow. As reported in our previous study, most of the cloned embryos were arrested at between sphere and 50\%-epiboly stages[15]. By using a SSH approach, we have totally screened out 50 differentially expressed genes in the cloned embryos at sphere stage. Among them, about $10 \%$ are related to redox function, such as selenoprotein W1, 5-lipoxygenase and glutaryl-coenzyme dehydrogenase etc; about $6 \%$ are responsible for cell growth and division, including geminin, daz-like gene and cofactor of BRCA2 etc. Interestingly, a novel gene, K31, was found to be up-regulated in the cloned embryos at sphere stage. Real-time RT-PCR analysis showed that the mRNA abundance of K31 gene in the cloned embryos was about 15 -fold than that in normally fertilized zebrafish embryos (Fig. 1), which was agreement with the dot blotting assay.

\section{Cloning and characterization of $\mathrm{K} 3 \mathrm{I}$ gene}

Full-length cDNA of K31 gene was obtained from a SMART CDNA library. It is $1106 \mathrm{bp}$ in length with an open reading frame (ORF) of 342 bp encoding a putative protein of $113 \mathrm{aa}$, a 5' untranslated region (UTR) of $307 \mathrm{bp}$, and a 3' UTR of 457 bp. It contains an mRNA instable motif (ATTTA) and a poly(A) signal (AATAAA) followed by a poly(A) tail (Fig. 2).

Homology search of public database found three novel zebrafish protein sequences (CAK10721, CAK04277 and XP 696518) to be closer to K31 but no homologous known gene in other species (Fig. 3A). Secondary structure prediction by DNAstar software shows that K31 protein contains more $\alpha$-helices and $\beta$-folds but less turns structure and hydrophilicity regions, indicating its lipophilic trait. Predicated by SignalP 3.0 software, there is no signal peptide in $\mathrm{K} 31$ protein. Interestingly, the transmembrane helices analysis by TMHMM2.0 software shows that K31 protein contains a TMhelix of 23 amino acids (from aa32 to aa54) (Fig. 3B). Moreover, phosphor-

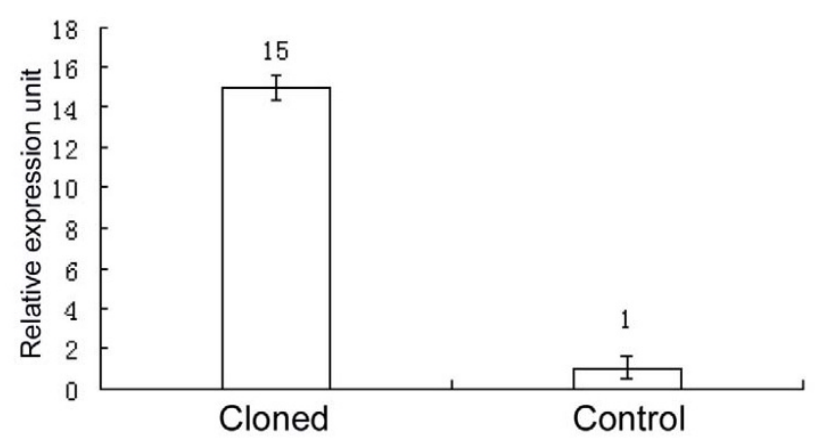

Figure I

Real time PCR analysis of K3 I gene. The expression of $\mathrm{K} 3 \mathrm{I}$ gene in cloned embryos is 15 times fold than in zebrafish embryos; GAPDH was used as an endogenous reference. 
GGACATACTGTCCTGTCTGCGCATGTGCAGACACATACCGCCATTTTTTTCTGAAGGCGCCAAG 64 GAGTATTTTGAAGCACTCTTTTGAATGCTGCATCCAGCTCTGCATTTTCGGTTATTCTCATATCTGATTGTGTTGGTGTGA 145 TGTGACCTAATTCTTAGgGGAGCTCATATTGCTTTGGCTAGAAGTGACATCTATCTTAAAAGGGCAGCAGTCATCAAGGCA 226 CTTTGCATCTACCTCGGTGAGGATGATGGACATCTCATTCAGGAGTATAAGGACATTGAAGGGGATGACATCCTGAGAGAC 307

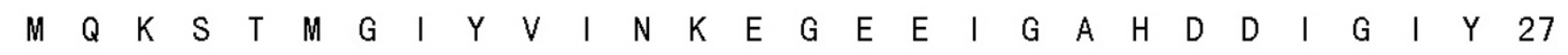
ATGCAGAAATCCACCATGGGCATATATGTCATCAACAAGGAGGGTGAAGAAAT TGGAGCTCATGATGACATTGGCATTTAT 388

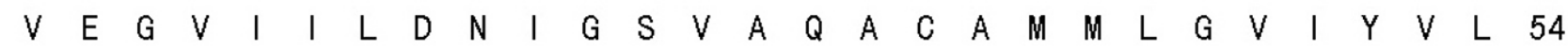
GTTGAAGGAGTAATCATTCTGGACAACATTGGATCTGTAGCTCAGGCATGTGCAATGATGCTTGGAGTCATCTATGTACTG 469 $\begin{array}{llllllllllllllllllllllllllllll}N & M & A & Y & P & K & K & L & K & Y & F & Y & E & F & I & Q & K & V & L & L & K & M & D & G & E & R & L & 81\end{array}$ AACATGGCTTACCCCAAAAAGCTGAAATACTTCTATGAATTCATTCAAAAAGTGCTCT TGAAAATGGATGGGGAGAGGCTT 550

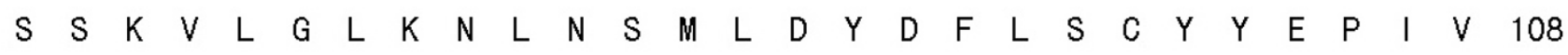
TCCTCCAAAGTCCTTGGACTAAAGAACCTAAATTCAATGCTGGACTATGATTTCCTCAGCTGCTATTATGAACCCATTGTT 631

$\begin{array}{lllllll}\text { I V F } & \text { T } & \text { E } & 113\end{array}$ $\begin{array}{ll}\text { ATTGTGTTTACGGAGTGA } & 649\end{array}$

TAAAGCATATTTAGTATGATGTGAAATGCAGCTGTAGAAGATGTTCCAAAGTGAGTTATGGACCTTAGTAATGTGTGTGGC 730 TATATGTAACAACAACAGTGGTTAACATTTAAATCTGTACTAGGTATGTTTTGGAGTATTGACTCAATATAAGTGTTTGCA 811 GTTTAATGCAATCTCACACAAGTTCATCAGTGTTTGCTGTCTTTCAGCTATTCTGGATCAATTGTTTTTGTCACGAATGGC 892 ACAATGTGAAATGAATGAAATTAATGAAATTAATGTATTTTATGTTAATGGATGATACTAGGGCATTTTGTTCTAAGAAA 973 GCAATTTGAGAAATGGTGACTACTGAGTTACATTACTGGCACTCTTGTTTGGGAGAGAAAAAATCTATCTCTTGGATTAGA 1054

\section{Figure 2}

Nucleotide sequence and deduced amino acid sequence of K3I gene. The accession no. was $A$ Y 885255 at Genbank. K3 I cDNA was I I 06 bp. Its ORF has 342 nucleotides, which codes II 3 aa. The nucleotides (lower row) and deduced amino acids (upper row) are numbered at the right side of the sequences, respectively. Poly (A) signal (in the $3^{\prime}$ UTR) is underlined. The start codon (ATG) is in bold and the stop codon (TAA) is indicated by an asterisk. An unstable motif (ATTTA) is doubly underlined.

ylation sites analysis by NetPhos 2.0 Server shows that there is a phosphorylation site $\left(\mathrm{Tyr}_{9}\right)$ in the N-terminal and four phosphorylation sites $\left(\operatorname{Ser}_{82}, \operatorname{Ser}_{83}, \operatorname{Ser}_{93}\right.$ and $\mathrm{Tyr}_{97}$ ) in the C-terminal but no phosphorylation sites in the transmembrane region. The data above indicates that $\mathrm{K} 31$ protein may participate in signal transduction.

\section{Expression profile of $\mathrm{K} 3 \mathrm{I}$ during development}

To figure out the expression pattern of K31 gene, real-time RT PCR was performed. As shown in Fig. 4A, K31 transcripts were found in all the checked developmental stages and it was expressed maternally in the oocytes, indicating that K31 gene presents a characteristic of constitutive expression. WISH was performed to obtain the temporalspatial expression pattern of $\mathrm{K} 31$ gene and the results showed that K31 expression was detected in all stages, which was agreement with real-time RT-PCR results. In the ovary samples, the signals were obviously detected in the oocytes of different stages, clearly demonstrating the maternal expression of K31 (Fig. 4B). The maternally transmitted mRNA could be detected at 8-cell stage after fertilization (Fig. 4C). After mid-blastula transition of 
K31

(1) MQR STMGIYVINKEGE

Danio rerio hypothetical protein (20) LF TYLGEDEACLVKEYMGNQREEFLRD L TNTAMAICVIKKERDanio rerio novel protein 1 (130) LFTYLGEDEAC LVKEYMGNQREEFLKDLTNTAMAICVIKKERDanio rerio novel protein 2 (1) -----MRRSRLQEVI SLASGTDDVER $G$ I SSTVMGIYIIRSYD

K31 '(17) EIGAHDDIGIYVEGVII LDNIGSVAQACAMML GVIYVL NMAYE Danio rerio hypothetical protein (62) -- GDYEDI GIVVD GT VIIEQIK SVAQACALML GAIYVLDLAYE Danio rerio novel protein 1 (172) -- GDYEDIGIVVD GT VIIEQIK SVAQACALML GAIYVLD LAYE Danio rerio novel protein 2 (39) -- GKPQDVGIVIE GI KVLTNVG SVIMGFVVLFGLIYALDLRFE

K31 (60) KKLKYFYEFIQRVLLKMDGERL SSKVLGLKNLNSMLDYDFLSC Danio rerio hypothetical protein (103) KELKYYYEFAQRVLVQMNSDKL S SKVLILENSVIL------Danio rerio novel protein 1 (213) KEL KYYYEFAQRVLVQMNSDKL SSKVLILENSVIL------Danio rerio novel protein 2 (80) ENLKYTFEFIQKIIMNLDGHKL NPKIQQLKIKLF S------

A

TMHMM posterior probabilities for K31

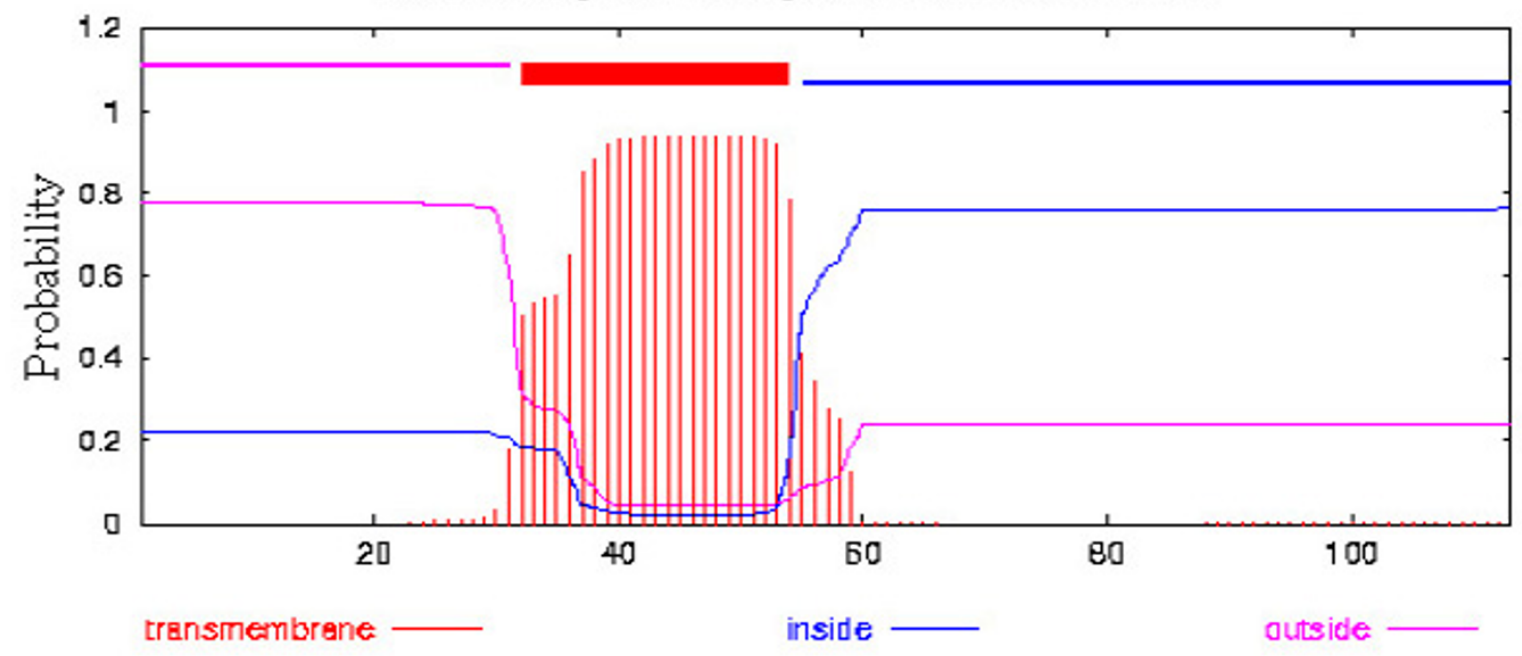

$\mathrm{B}$

\section{Figure 3}

Bio-information analysis of K3 I amino acids. A. Homologous alignment is analysed by BLAST program in NCBI. Therein, Danio rerio hypothetical protein (XP 6965I8), novel protein I (CAK I072I) and novel protein 2 (CAK04277) is 57\%, 57\% and $39 \%$ identity with $\mathrm{K} 3 \mathrm{I}$, respectively. B. The transmembrane helices are analysed by TMHMM 2.0 software. A transmembrane helices lies in the region from aa 32 to aa 54 .

zygotic genome activation, K31 was ubiquitously expressed in the whole embryos at blastula (Fig. 4D), gastrula (Fig. 4E), and mid-somitogeneis stages (Fig. 4F). At $1 \mathrm{dpf}$ (day post-fertilization) and 2 dpf of development, the signals were detected in the whole embryo with more intensive labeling at the anterior tissues (Fig. 4G, H), including an obvious labeling of the hatching gland (Fig. $4 \mathrm{I}$ ) and the pectoral fin territory (Fig. 4J).

\section{Sub-cellular localization and ectopic over-expression of K3I gene}

To study the sub-cellular localization of K31 gene, we constructed pK31-EGFP plasmid with K31 coding sequence fused to EGFP gene. The pK31-EGFP and pEGFP-N3 (as negative control) were transfected in EPC cells, respectively. At $24 \mathrm{~h}$ after transfection, Hochest 33342 was used to stain cell nuclei and sub-cellular localization of K31 

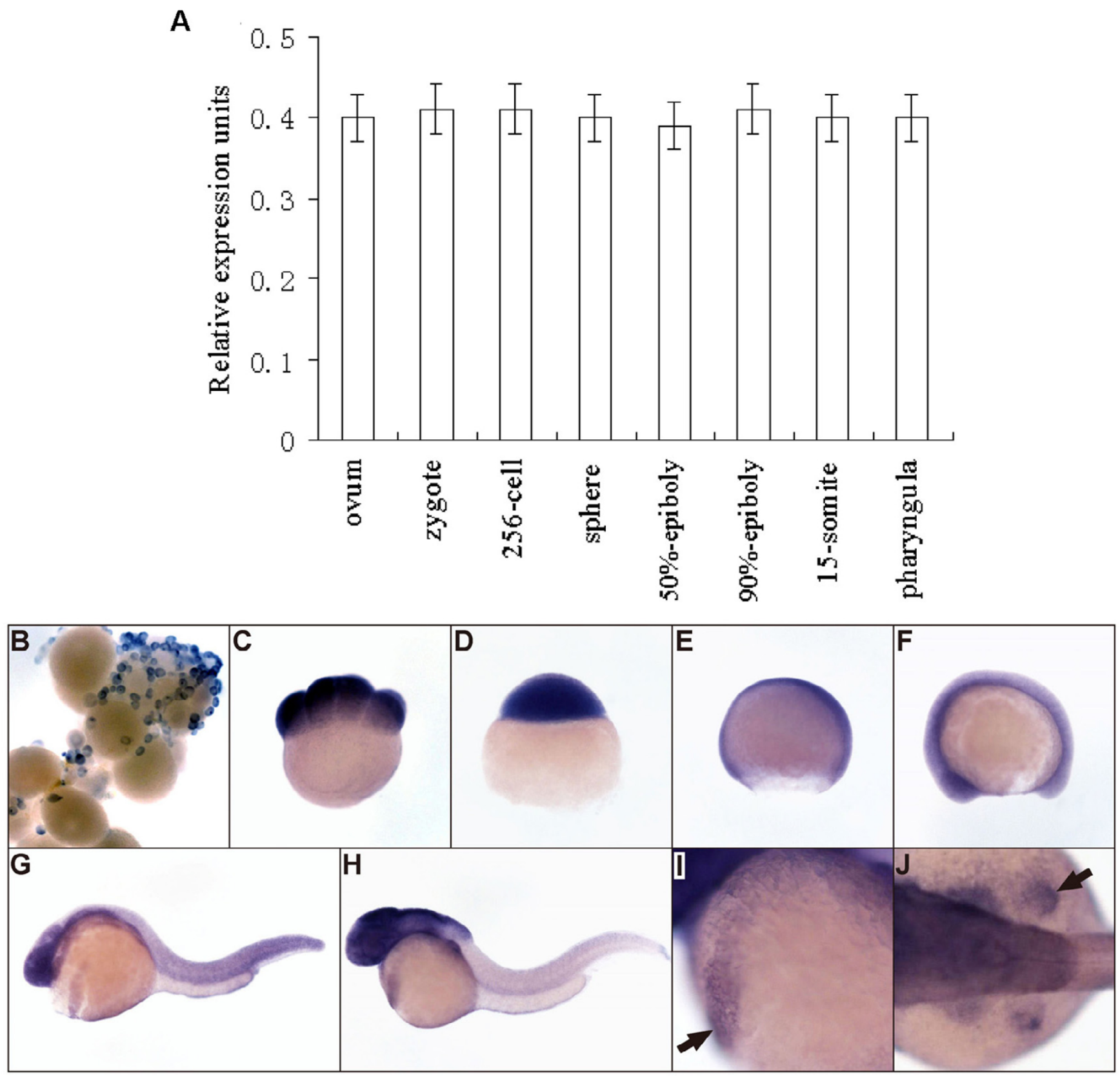

\section{Figure 4}

Analysis of the expression level of $\mathrm{K} 3 \mathrm{I}$ gene at different developmental stages in zebrafish. (A) Real time RT-PCR analysis of $\mathrm{K} 3 \mathrm{I}$ transcription during development. $\mathrm{K} 3 \mathrm{I}$ transcripts are expressed maternally in the ovum. From zygote to pharyngula period, $\mathrm{K} 3 \mathrm{I}$ has a characteristic of constitutive expression gene. GAPDH was used as endogenous reference. (B-J) Expression of $\mathrm{K} 3 \mathrm{I}$ transcripts as detected by WISH during embryogenesis in zebrafish. (B) ovary, (C) 8-cell stage (I.25 hpf, hours post-fertilization), (D) sphere stage (4 hpf), (E) 75\% epiboly ( $8 \mathrm{hpf}$ ), (F) 10-somite stage (I3 hpf), (G) I dpf (day post-fertilization), (F) $2 \mathrm{dpf}$, (I) $2 \mathrm{dpf}$ embryo with arrow indicating the hatching gland, (J) 2 dpf embryo with arrow indicating the pectoral fin. Embryos in C-I are lateral views, C-E with the animal pole to the top, and the dorsal to the right, F-I with dorsal to the top and anterior to the left; embryo in J is dorsal view, with anterior to the left. 

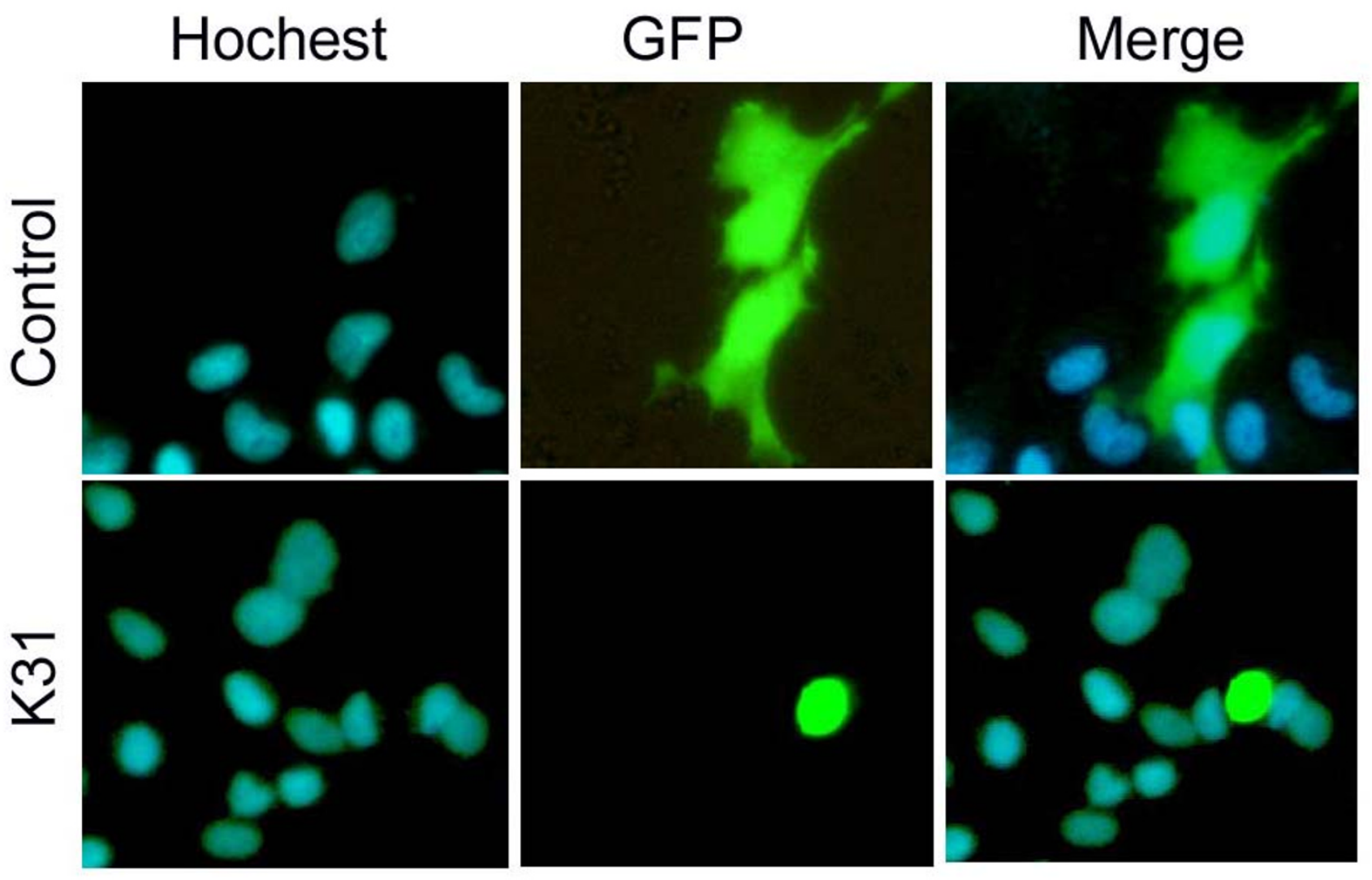

\section{Figure 5}

Sub-cellular localization of pEGFP-K3 I expressed in EPC cells. The sub-cellular localization of control (pEGFP-N3) and PEGFP-K3I expressed GFP signals in EPC cells was in the upper and lower rows, respectively. Therein, blue signals represented the cell nuclei stained by Hochest 33342; Green signals represented the expression of pEGFP-N3 and pEGFP-K3I fluorescence proteins in EPC cells, respectively; Merge represented overlapping the images of pEGFP-N3 or pEGFP-K3I fluorescent protein with the images of cell nuclei stained by Hochest 33342 . All three panels had the same view field at $24 \mathrm{~h}$ after transfection.

was judged by the co-localization of GFP protein. The results showed that K31-EGFP fusion protein located in cytoplasm, rather than in nucleus (Fig. 5).

To study the biological effects after ectopic over-expression of K31 gene, we visualized the EPC cells nuclei using Hochest 33342 at $24 \mathrm{~h}, 28 \mathrm{~h}$ and $32 \mathrm{~h}$ after transfection. We found the cells were dead after $32 \mathrm{~h}$, which was validated by trypan blue staining. Following comparative analysis in white field and the overlapping of the stained nuclei with green fluorescence which indicates the overexpression of K31-GFP fusion protein, we conclude that ectopic over-expression of $\mathrm{K} 31$ in cytoplasm causes the lethality of cultured fish cells (Fig. 6).

\section{Discussion}

Nuclear transfer in fish has been successfully manipulated for over 40 years [16]. Cross-genus cloned fish derived from common carp nuclei and goldfish enucleated eggs was given birth as reported by Sun et al [6]. In our recent study, we not only demonstrated the success of cloned embryos derived from zebrafish nuclei and rare minnow enucleated eggs, but also the success of cloned embryos derived from rare minnow nuclei and zebrafish enucleated eggs by SCAR approaches [17]. Samples used in the present study were strictly chosen at sphere stage of embryogenesis as described by Kimmel et al [18] to ensure the accuracy. In single cloned embryo, SCAR PCR was performed with primers distinguished rare minnow from zebrafish, revealing the success of nuclear transfer [17]. Consequently, the novel gene, K31, is certainly resulted 
$24 \mathrm{~h}$
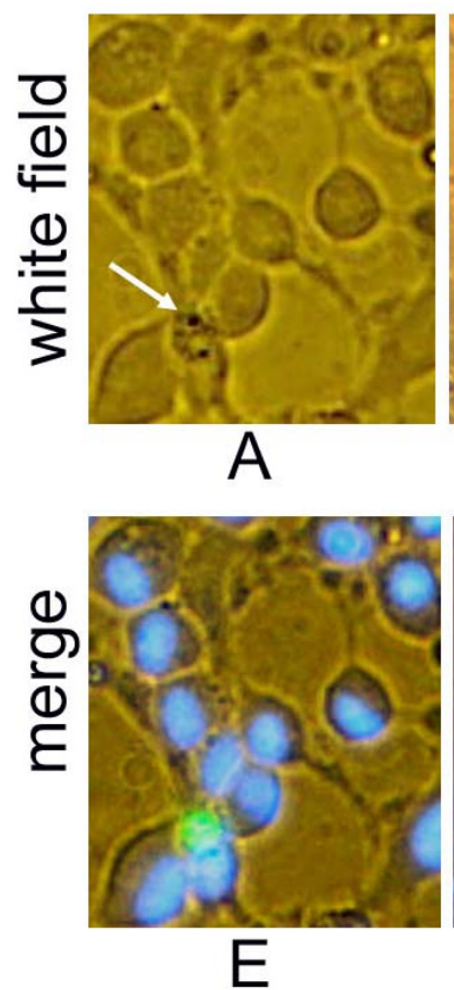

$28 \mathrm{~h}$

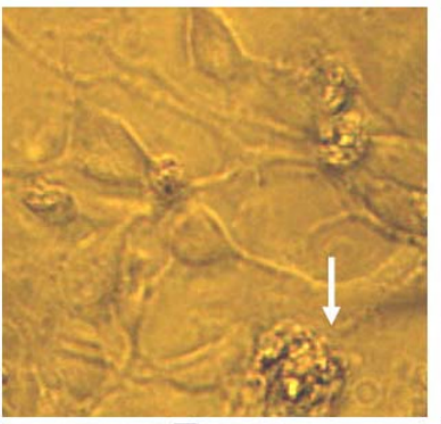

B

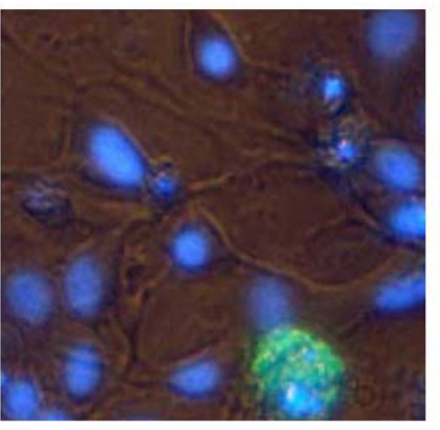

F
$32 \mathrm{~h}$

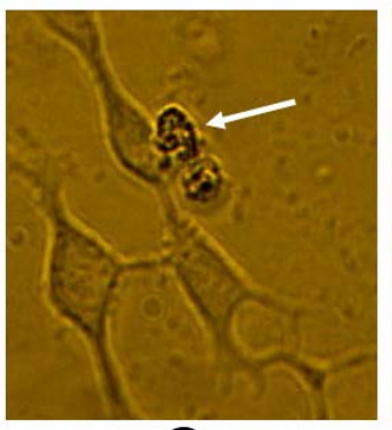

C

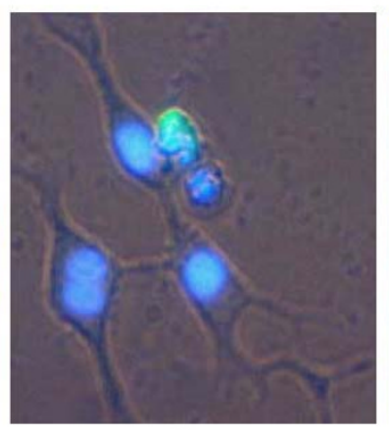

G trypan blue
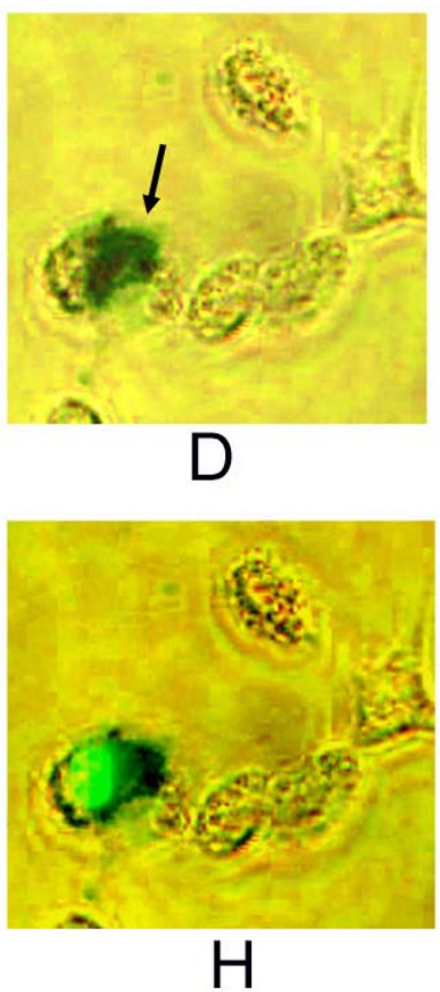

Figure 6

Ectopic over-expression of K3I protein at different times after transfection. (A-C) the shapes of EPC cells taken in white field at $24 \mathrm{~h}, 28 \mathrm{~h}$ and $32 \mathrm{~h}$ after transfection by PEGFP-K3I, respectively. The white arrows indicate the supposed dying cells. (E-G) the overlaps of the EGFP fluorescence and the cell nuclei stained by Hochest 33342 for A-C, respectively. (D, $H$ ) confirmation of the supposed dying cells using trypan blue dye; $D$ is the shapes of EPC cells taken in white field at $32 \mathrm{~h}$ after transfection and stained by trypan blue; The black arrow indicate the dead cell. $\mathrm{H}$ is the overlaps of the EGFP fluorescence and the dead cell stained by trypan blue. Green, blue and dark blue signals represented GFP fluorescence, Hochest 33342 stained nuclei and trypan blue stained dead cell, respectively.

from the nucleo-cytoplasmic interaction between zebrafish and rare minnow, excluding any artificial interfere.

Previous studies demonstrated that the majority of embryos produced by nuclear transfer were compromised because they were unable to develop past the early development stages [19]. A common hypothesis is that inefficient reprogramming of the donor nucleus results in inappropriate expression of genes required for embryonic development. Gene expression analysis of individual embryos will undoubtedly yield new insights into the regulatory mechanisms involved in nuclear transfer inducing reprogramming and embryonic development. In the present study, a novel gene, K31 was found to be overexpressed in cross-subfamily cloned embryos by $\mathrm{SSH}$ approach. To our knowledge, this is the first report of gene expression analysis in cross-subfamily cloned embryos. Interestingly, K31 transcripts were found in all embryonic development stages of zebrafish and K31 was also expressed maternally in ovum, but its ectopic over-expression caused the EPC cells to die during the cell culture. Result of sub-cellular localization indicates that K31 protein can not penetrate the nuclei, and it may be participate in signal transduction by its five putative phosphorylation sites. Previous studies indicated that the reprogramming efficiency of cloned embryos was influenced by many factors, such as epigenetic changes like DNA methylation and XCI patterns[20,21], failure to suppress previously active gene transcription as well as failure to activate previously inactive genes [22-24], failure of chromatin remodeling [21,25-27] and mitochondria effects of proper reprogramming [28], etc. Yet, we can conclude that nucleo-cytoplasmic interaction in such cross-subfamily 
Table I: Primers used in the present study

\begin{tabular}{ll}
\hline Names & Sequences \\
\hline SMART F & 5-CAACGCAGAGTACGCGGG-3 \\
SMART R & TCAACGCAGAGTACT(I6) \\
K3I F & 5-CTTGAAAATGGATGGGGAGA-3 \\
K3I R & 5-ACAATGGGTTCATAATAGCAGC-3 \\
K3IDW F & 5-AACTGCAGATGCAGAAATCCACCATGGG-3 \\
K3IDW R & 5-CGGGATCCCTCCGTAAACACAATAACAATGG-3 \\
GAPDH F & 5-GTGTAGGCGTGGACTGTGGT-3 \\
GAPDH R & 5-TGGGAGTCAACCAGGACAAATA-3 \\
\hline
\end{tabular}

cloned embryos caused the over-expression of K31 gene. Further reliable studies in a comprehensive way should provide solid evidences to unveil whether K31 gene can affect the nuclear reprogramming in cloned embryos.

\section{Conclusion}

Cross-species nuclear transfer can be used to maintain limited populations of highly endangered species, especially when the oocytes of these species are difficult to obtain. However, most embryos produced by cross-species nuclear transfer were compromised because they were unable to develop to later developmental stages. Therefore, gene expression analysis of cross-species cloned embryos is necessary. Here we used two laboratory fish species, rare minnow and zebrafish as cross-subfamily nuclear transfer model and report $\mathrm{K} 31$ gene as an up-regulated gene in fish cross-subfamily cloned embryos. Importantly, ectopic over-expression of $\mathrm{K} 31$ gene can cause lethality of EPC cells in the cell culture, which gave hint that why most of the cloned embryos were developmentally arrested in between the stages of sphere and $50 \%$ epiboly.

\section{Methods \\ Preparation of cross-subfamily cloned embryos and non- cloned embryos}

The cross-subfamily cloned embryos were generated by nuclear transfer as described by Sun et al. [6], with nuclei derived from zebrafish at blastula stage and the enucleated unfertilized eggs of rare minnow. Meanwhile, batches of non-cloned zebrafish embryos were produced by in vitro fertilization. All embryos were incubated in Holtfreter's solution at $28^{\circ} \mathrm{C}$, and collected at sphere stage [18]. The manipulations in the experiment adhered to Guidelines for Animal Use in Biomedical Research Laboratories (ILAR, 1996).

\section{SMART CDNA synthesis and construction of SSH CDNA libraries}

Total RNA was extracted from cloned and zebrafish embryos by $\mathrm{SV}^{\mathrm{Tm}}$ total RNA kit (Promega, WI, USA). Poly(A)+ RNA was purified with Poly(A)Tract mRNA Isolation system (Promega WI, USA) and then used to syn- thesize SMART cDNA according to the instructions of $\mathrm{BD}$ SMART cDNA Library Construction Kit (Clontech, CA, USA). The forward subtracted cDNA library was obtained using tester dscDNAs from cloned embryos and driver dscDNA from zebrafish embryos. At the same time, the reverse subtracted cDNA library was obtained using tester dscDNAs from zebrafish embryos and driver dscDNA from cloned embryos. To evaluate the efficiency of the cDNA subtraction, reverse transcriptase PCR was performed with GAPDH (glyceraldehyde-3-phosphate dehydrogenase) primers in forward subtracted and unsubtracted cDNA. After the secondary PCR, the PCR products generated by SSH were cloned into the pGEM-T Easy vector (Promega, WI, U.S.A). PCR and dot blots were applied to screen improper reprogramming genes from the subtracted cDNA library as described by Sung et al [29].

\section{RACE-PCR and real-time PCR analysis}

RACE-PCR was used to clone the full-length CDNA of K31 gene. Using SMART cDNA as templates, the combination of universal primer SMART F and K31 R, universal primer SMART R and K31 F was used for 5' and 3' RACE PCR, respectively (Table 1 ). The generated PCR products were sequenced, and the full-length cDNA of K31 was composed of 5' RACE sequence and 3' RACE sequence.

The relative quantification with real-time RT-PCR was done as described by the manufacturer (Applied Biosystems, USA) with slight modification. In brief, the samples were placed in 96 well plates and amplified in an automated fluorometer (ABI PRISM 7000 Sequence Detection System, Applied Biosystems). Each PCR proceeded in 30 $\mu$ l SYBR Green PCR buffer (Applied Biosystems) containing $400 \mathrm{nM} \mathrm{K} 31 \mathrm{~F}$ and $\mathrm{K} 31 \mathrm{R}$ primers, $1 \mathrm{U}$ AmpliTaq Gold DNA polymerase, $2.5 \mathrm{mM}$ dNTPs, $0.5 \mathrm{U}$ AmpErase UNG, $3 \mathrm{mM} \mathrm{MgCl} 2$ and $50 \mathrm{ng}$ cloned embryos or non-cloned embryos CDNA template. Amplification conditions were 2 min at $50^{\circ} \mathrm{C}, 10 \mathrm{~min}$ at $95^{\circ} \mathrm{C}, 40$ cycles of $30 \mathrm{~s}$ at $95^{\circ} \mathrm{C}$ and $60 \mathrm{~s}$ at $60^{\circ} \mathrm{C}$. All samples were analyzed in triplet and the results were expressed as relative fold of the expression of the GAPDH gene with 2 [-deltadeltaCT] method with correction for different amplification efficiencies (the amplification efficiency of cloned embryos or zebrafish embryos is 0.995 or 0.990 , respectively) [30].

\section{Data mining and bio-information analyses}

Homology search of K31 gene was performed on the sequences listed in EMBL/GenBank/DDBJ databases using PHI- and PSI-BLAST, EST-BLAST and Protein-protein BLAST (blastp) at the web site of the National Center of Biotechnology Information (NCBI) [31]. Secondary structure analysis of K31 protein sequence was performed by DNAstar software (Lasergene, Madison, Wis.). Transmembrane helices, phosphorylation sites and signal pep- 
tide were predicted by TMHMM2.0 software [32], NetPhos 2.0 software [33] and SignalP 3.0 software [34], respectively.

\section{Analysis of expression pattern by real time RT-PCR and whole-mount in situ hybridization (WISH)}

Zebrafish embryos were obtained by in vitro fertilization and raised in Holtfreter's solution $(0.35 \% \mathrm{NaCl}, 0.01 \%$ $\mathrm{KCl}$, and $0.01 \% \mathrm{CaCl} 2$ ) at $28^{\circ} \mathrm{C}$. Embryos were staged according to Kimmel et al [18]. Total RNA of 8 samples (ovum, zygote, 256-cell stage, sphere stage, 50\%-epiboly stage, 90\%-epiboly stage, 15-somite stage, pharyngula period) was separately isolated using $\mathrm{SV}^{\mathrm{rM}}$ total RNA kit (Promega, WI, USA). Then, $3 \mu \mathrm{g}$ total RNA was reverse transcribed (RT) for each sample and $2 \mu \mathrm{l}$ of the RT product was amplified to quantify K31 transcripts by real-time RT-PCR. The manipulation of real-time RT-PCR was all the same as described above (to see materials and methods 2.3).

For WISH, embryos were fixed in MEMPFA (100 mM Mops (Sigma), pH 7.4; 2 mM EGTA (Sigma); $1 \mathrm{mM}$ MgSO4 (Merck); 4\% (w/v) paraformaldehyde (Sigma) at different developmental stages. For generation of fulllength K31 antisense probes, pBluescripts KS II-K31 plasmids were linearized and used as templates for synthesis of DIG-labeled antisense RNA (Roche). RNA probe was purified using RNeasy columns (QIAGEN). In situ hybridization essentially following the protocol described by Thisse et al. [35]. WISH was performed with a probe concentration of $100 \mathrm{ng} / \mathrm{mL}$ at $65^{\circ} \mathrm{C}$. As a control, WISH with similarly produced sense probes was performed. Images of zebrafish embryos were recorded using an Olympus SZX12 microscope and a digital camera.

\section{Cell culture and sub-cellular localization and ectopic over- expression of $\mathrm{K} 3 \mathrm{I}$}

EPC cells from carp (Cyprinus carpio) were cultured in medium 199 supplemented with $10 \%$ fetal calf serum (FCS) and antibiotics (100 U/ml penicillin and $100 \mu \mathrm{g} / \mathrm{ml}$ streptomycin). Cultures were maintained at $28^{\circ} \mathrm{C}$ in an atmosphere of $5 \% \mathrm{CO}_{2}$ in air.

For fluorescence microscopy, the coding region of K31 gene was amplified using K31DW primers (Table 1) and cloned into pEGFP-N3 (BD Biosciences, PaloAlto, CA, USA) using PstI and BamHI sites. After sequencing validation, the p K31-EGFP construct was transfected into EPC cells using Lipofectamine 2000 reagent (Invitrogen). After 24, 28 and 32 h culture, cells were removed by trypsin/ EDTA and analysed for sub-cellular localization and ectopic over-expression with $5 \mathrm{mg} / \mathrm{L}$ Hochest 33342 (Calbiochem) to stain the nuclei of cells as described [36] and $0.4 \%$ trypan blue dye (sigma) to stain the dead cells as described [37], respectively.

\section{Abbreviations}

ORF, open reading frame; $\mathrm{SSH}$, suppression subtractive hybridization; WISH, whole-mount in situ hybridization; RACE, rapid amplification cDNA ends; SMART, switch mechanism at the 5 ' end of RNA templates.

\section{Authors' contributions}

DSP, YHS and ZYZ designed the experiment, DSP performed the molecular and genetic analysis and is the primary author of the manuscript. YHS and ZYZ conceived the experiment, supervised the study, and helped to draft the manuscript and approved the final version. CHC, SPC, YPW and WH participated in primer design, cell culture and sub-cellular localization analysis. All authors read and approved the manuscript.

\section{Acknowledgements}

This work was supported by the State Key Fundamental Research of China (Grant No 2004CBI I 7406) and the National Natural Science Foundation of China (Grant No. 3077II 100 and 30700607). In addition, the authors are grateful to Ming Li for supplying experimental materials and Qiya Zhang for providing EPC cells.

\section{References}

I. Gurdon JB, Byrne JA, Simonsson S: Nuclear reprogramming and stem cell creation. Proc Natl Acad Sci U S A 2003, 100 Suppl I: I|819-I |822

2. Smith SL, Everts RE, Tian XC, Du F, Sung LY, Rodriguez-Zas SL, Jeong $B S$, Renard JP, Lewin HA, Yang X: Global gene expression profiles reveal significant nuclear reprogramming by the blastocyst stage after cloning. Proc Natl Acad Sci U S A 2005, I 02(49): I 7582-I7587.

3. Loi P, Ptak G, Barboni B, Fulka J Jr., Cappai P, Clinton M: Genetic rescue of an endangered mammal by cross-species nuclear transfer using post-mortem somatic cells. Nat Biotechnol 2001 , I 9( I 0):962-964.

4. Tung TC, Wu SC, Tung YYF, Yan SY, Tu M, Lu TY: Nuclear transplantation in fish. Science Bulletin, Academia Sinica (in Chinese) 1963 , 7:60-6I.

5. Yan SY: The Nucleo-cytoplasmic Interaction as Revealed by Nuclear Transplantation in Fish. In Cytoplasmic Organization Systems: A Primer in Developmental Biology Edited by: Malacinski GM. New York, , McGraw-Hill; 1989:6I-8I.

6. Sun YH, Chen SP, Wang YP, Hu W, Zhu ZY: Cytoplasmic impact on cross-genus cloned fish derived from transgenic common carp (Cyprinus carpio) nuclei and goldfish (Carassius auratus) enucleated eggs. Biol Reprod 2005, 72(3):510-5 I5.

7. He S, Liu H, Chen Y, Kuwahara M, Nakajima T, Zhong Y: Molecular phylogenetic relationships of Eastern Asian Cyprinidae (pisces: cypriniformes) inferred from cytochrome b sequences. Sci China C Life Sci 2004, 47(2): I30-I38.

8. Pei DS, Sun YH, Chen SP, Wang YP, Zhu ZY: Cloning and characterization of cytochrome c oxidase subunit I (COXI) in Gobiocypris rarus. DNA Seq 2007, I 8(I): I-8.

9. Grunwald DJ, Eisen JS: Headwaters of the zebrafish -- emergence of a new model vertebrate. Nat Rev Genet 2002, 3(9):717-724.

10. Key B, Devine CA: Zebrafish as an experimental model: strategies for developmental and molecular neurobiology studies. Methods Cell Sci 2003, 25(1-2): I-6.

II. Wang J: Acute effects of high concentration of dissolved free carbon dioxide and low dissolved oxygen on rare minnow. Acta Hydrobiologica Sinica (in Chinese) 1995, 19:84-88.

12. Qun-Fang Z, Gui-Bin J, Ji-Yan L: Effects of sublethal levels of tributyltin chloride in a new toxicity test organism: the Chinese rare minnow (Gobiocypris rarus). Arch Environ Contam Toxicol 2002, 42(3):332-337. 
13. Zhong J, Wang Y, Zhu Z: Introduction of the human lactoferrin gene into grass carp (Ctenopharyngodon idellus) to increase resistance against GCH virus. Aquaculture 2002, 21 4:93-101.

14. Wang J, Cao W: Gobiocypris rarus and fishes as laboratory animals. Trans Chin Ichthyol Soc 1997, 6: I44-I52.

15. Pei DS, Sun YH, Chen SP, Wang YP, Hu W, Zhu ZY: Identification of differentially expressed genes from the cross-subfamily cloned embryos derived from zebrafish nuclei and rare minnow enucleated eggs. Theriogenology 2007, 8(9): | 282- I29|.

16. Zhu ZY, Sun YH: Embryonic and genetic manipulation in fish. Cell Res 2000, I0(I): 17-27.

17. Hu W, Pei DS, Dai J, Chen SP, Sun YH, Wang YP, Zhu ZY: Identification and application of SCAR markers in detecting crossspecies cloned embryos between zebrafish and rare minnow. In Chinese High Technology Letters Volume 16. Issue 9 United States; 2006:959-963.

18. Kimmel CB, Ballard WW, Kimmel SR, Ullmann B, Schilling TF: Stages of embryonic development of the zebrafish. Dev Dyn 1995, 203(3):253-310

19. Hill JR, Winger QA, Long CR, Looney CR, Thompson JA, Westhusin ME: Development rates of male bovine nuclear transfer embryos derived from adult and fetal cells. Biol Reprod 2000, 62(5): $1135-1140$

20. Santos F, Zakhartchenko V, Stojkovic M, Peters A, Jenuwein T, Wolf E, Reik W, Dean W: Epigenetic marking correlates with developmental potential in cloned bovine preimplantation embryos. Curr Biol 2003, I3(13): I|| |6-| | 2 I.

21. Nolen LD, Gao S, Han Z, Mann MR, Gie Chung Y, Otte AP, Bartolomei MS, Latham KE: $\mathbf{X}$ chromosome reactivation and regulation in cloned embryos. Dev Biol 2005, 279(2):525-540.

22. Sun $Y$, Chen $S$, Wang $Y$, Zhu Z: The onset of foreign gene transcription in nuclear-transferred embryos of fish. Sci China $C$ Life Sci 2000, 43:597-605.

23. Boiani M, Eckardt S, Scholer HR, McLaughlin KJ: Oct4 distribution and level in mouse clones: consequences for pluripotency. Genes Dev 2002, I 6(10): 1209-1219.

24. Bortvin A, Eggan K, Skaletsky H, Akutsu H, Berry DL, Yanagimachi R, Page DC, Jaenisch R: Incomplete reactivation of Oct4-related genes in mouse embryos cloned from somatic nuclei. Development 2003, I30(8): I673-1680.

25. Moreira PN, Robl JM, Collas P: Architectural defects in pronuclei of mouse nuclear transplant embryos. I Cell Sci 2003, I I 6(Pt 1 8):37| 3-3720.

26. Sullivan EJ, Kasinathan S, Kasinathan P, Robl JM, Collas P: Cloned calves from chromatin remodeled in vitro. Biol Reprod 2004, 70(I): I46-153.

27. Zhang LS, Zhang KY, Yao LJ, Liu SZ, Yang CX, Zhong ZS, Zheng YL, Sun QY, Chen DY: Somatic nucleus remodelling in immature and mature Rassir oocyte cytoplasm. Zygote 2004, I 2(2): 179-184.

28. Hiendleder $S$, Zakhartchenko $V$, Wenigerkind $H$, Reichenbach HD Bruggerhoff K, Prelle K, Brem G, Stojkovic M, Wolf E: Heteroplasmy in bovine fetuses produced by intra- and inter-subspecific somatic cell nuclear transfer: neutral segregation of nuclear donor mitochondrial DNA in various tissues and evidence for recipient cow mitochondria in fetal blood. Bio Reprod 2003, 68(I):159-166.

29. Sung YK, Moon C, Yoo JY, Moon C, Pearse D, Pevsner J, Ronnett GV: Plunc, a member of the secretory gland protein family, is upregulated in nasal respiratory epithelium after olfactory bulbectomy. J Biol Chem 2002, 277(I5): 12762-12769.

30. Livak KJ, Schmittgen TD: Analysis of relative gene expression data using real-time quantitative PCR and the 2(-Delta Delta C(T)) Method. Methods 200I, 25(4):402-408.

31. Altschul SF, Madden TL, Schaffer AA, Zhang J, Zhang Z, Miller W, Lipman DJ: Gapped BLAST and PSI-BLAST: a new generation of protein database search programs. Nucleic Acids Res 1997, 25(I7):3389-3402.

32. Sonnhammer EL, von Heijne G, Krogh A: A hidden Markov model for predicting transmembrane helices in protein sequences. Proc Int Conf Intell Syst Mol Biol 1998, 6: 175-182.

33. Blom N, Gammeltoft S, Brunak S: Sequence and structure-based prediction of eukaryotic protein phosphorylation sites. J Mol Biol 1999, 294(5): 1351-1362.
34. Bendtsen JD, Nielsen H, von Heijne G, Brunak S: Improved prediction of signal peptides: SignalP 3.0. J Mol Biol 2004, 340(4):783-795.

35. Thisse C, Thisse B, Schilling TF, Postlethwait JH: Structure of the zebrafish snaill gene and its expression in wild-type, spadetail and no tail mutant embryos. Development 1993, II 9(4): I203-12I5.

36. Song Z, Wu M: Identification of a novel nucleolar localization signal and a degradation signal in Survivin-deltaEx3: a potential link between nucleolus and protein degradation. Oncogene 2005, 24(16):2723-2734.

37. Dohn M, Jiang ], Chen X: Receptor tyrosine kinase EphA2 is regulated by $\mathbf{5 3}$-family proteins and induces apoptosis. Oncogene 200I, 20(45):6503-65I5

Publish with Biomed Central and every scientist can read your work free of charge

"BioMed Central will be the most significant development for disseminating the results of biomedical research in our lifetime. "

Sir Paul Nurse, Cancer Research UK

Your research papers will be:

- available free of charge to the entire biomedical community

- peer reviewed and published immediately upon acceptance

- cited in PubMed and archived on PubMed Central

- yours - you keep the copyright
BioMedcentral 